\title{
FERRAJOLI Y EL NEOCONSTITUCIONALISMO PRINCIPIALISTA. ENSAYO DE INTERPRETACIÓN DE ALGUNAS DIVERGENCIAS *
}

\author{
Luis Prieto Sanchís \\ Universidad de Castilla-La Mancha
}

RESUMEN. La teoría jurídica de FERRAJOLI asume el nuevo paradigma del Estado constitucional de Derecho. Sin embargo se distancia de las construcciones más habituales del neoconstitucionalismo en dos aspectos capitales, que aquí son objeto de análisis. En el aspecto metodológico o conceptual se mantiene firmemente la perspectiva ilustrada y positivista de la separación conceptual entre Derecho y moral. En el aspecto teórico, se mantiene una posición más escéptica o menos confiada en las posibilidades de la argumentación jurídica, lo que tiene dos consecuencias principales: una visión más restrictiva de la aplicación directa de la Constitución y una visión no conflictivista de los derechos fundamentales.

Palabras clave: FeRRAJOLI, neoconstitucionalismo, separación conceptual entre Derecho y moral, conflictualismo, derechos fundamentales.

ABSTRACT. The legal theory of FERRAJOLI adopts the new paradigm of constitutional State of Law. However it takes exception to the more frequent constructions of neoconstitutionalism for two prime aspects, which will be considered in the text. In the methodological or conceptual sense it firmly maintains the enlightened and positivist stance of the conceptual separation between law and morals. In the theoretical sense, it differs from neoconstitutionalism in that a more sceptical or doubtful approach is adopted with regards to the possibilities of legal argumentation, resulting in two main consequences: a more restricted view of the direct application of the Constitution as well as a non conflictualist view of the fundamental rights.

Keywords: FERRAJOLI, neoconstitutionalism, conceptual separation between law and morals, conflictualism, fundamental rights.

* Fecha de recepción: 10 de enero de 2011. Fecha de aceptación: 7 de febrero de 2011. 


\section{UNA PRIMERA PRECISIÓN TERMINOLÓGICA}

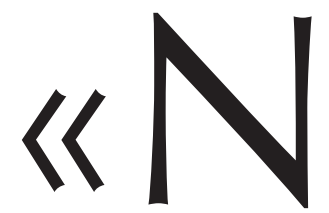

eoconstitucionalismo» es un término de reciente acuñación teórica y, a mi juicio, ello permite y facilita las aproximaciones más estipulativas, pues como sucede con todos los neologismos no es preciso guardar fidelidad a ninguna tradición semántica. No parece existir, sin embargo, un significado admitido de manera uniforme. En general, creo que con la expresión «neoconstitucionalismo» se alude a una concepción del Derecho desarrollada en el marco o a partir de los sistemas jurídicos nacidos del constitucionalismo contemporáneo, pero sin que en verdad resulten claras las tesis que componen esa nueva concepción, ni tampoco los rasgos precisos que se tienen como relevantes de tales sistemas. En este sentido y tras advertir sobre algunos usos que son fuente de confusión, FERRAJOLI propone denominar constitucionalismo (a secas) a un modelo político cuyo «rasgo distintivo será identificable con la existencia positiva de una lex superior a la legislación ordinaria, con independencia de las diversas técnicas adoptadas para garantizar su superioridad», modelo que se opondría o que sería la superación del Estado legislativo de Derecho. A su vez, y si he entendido bien, expresiones como neoconstitucionalismo, constitucionalismo iusnaturalista o principialista, constitucionalismo positivista o garantista u otras análogas parece que designarían concepciones diferentes a propósito del actual Estado constitucional ${ }^{1}$.

No tengo nada que objetar a estas estipulaciones dirigidas a distinguir con mayor claridad entre lo que es un modelo de organización política o un sistema de Derecho positivo y lo que son las diferentes interpretaciones o concepciones construidas a partir del mismo. Me parece, sin embargo, que la caracterización que ofrece FERRAJOLI del constitucionalismo, aunque certera, resulta excesivamente genérica y por ello mismo insuficiente para dar cuenta de los rasgos que singularizan al Estado constitucional contemporáneo y que precisamente permiten distinguirlo del Estado legislativo de Derecho $^{2}$. La mera existencia de una lex superior a la legislación ordinaria bien pudiera predicarse, por ejemplo, del modelo propuesto por KELSEN ${ }^{3}$, con el que seguramente culmina el Derecho constitucional europeo de preguerra, pero resulta bastante pobre para explicar el constitucionalismo posterior a 1945. Tal vez deberíamos acuñar

${ }^{1}$ L. FERRAJOLI, «Constitucionalismo principialista y constitucionalismo garantista», epígrafe 1, 6. No obstante, más adelante, en el epígrafe 3, se habla de un constitucionalismo garantista como modelo de Derecho, como teoría del Derecho y como filosofía política. Si no me equivoco, en realidad el constitucionalismo garantista entendido como modelo de Derecho describe los rasgos del Estado constitucional contemporáneo y, por tanto, los presupuestos jurídico-políticos que han de ser comunes a las distintas concepciones.

2 El propio FERRAJOLI suele realizar aproximaciones mucho más precisas: si la regulación de la forma de las leyes caracteriza al positivismo y al Estado de Derecho en sentido débil, «la regulación de sus significados mediante normas sustantivas caracteriza en cambio al constitucionalismo y al Estado de Derecho en sentido fuerte, que exige que todos los poderes, incluso el legislativo, se hallen sometidos a límites y vínculos de contenido», Principia Iuris. Teoria del diritto e della democrazia, Bari, Laterza, 2007, vol. I, 567.

3 KeLSEN, en efecto, asume perfectamente la idea de Constitución como lex superior, pero muestra numerosos reparos a la posibilidad de que la misma incorpore derechos fundamentales u otras normas sustantivas que condicionen lo decidible por el legislador. Vid., por ejemplo, «La garantía jurisdiccional de la Constitución (la justicia constitucional)», en J. RUIZ MANERO (ed.), Escritos sobre la democracia y el socialismo, Madrid, Debate, 1988,142 y ss. 
una nueva expresión que no dé lugar a confusiones, pero en cualquier caso de algún modo hay que individualizar el modelo constitucional desarrollado en la segunda mitad del siglo XX respecto de los precedentes. En otro lugar he propuesto cuatro rasgos o criterios fundamentales sin cuya concurrencia seguramente no hubieran podido concebirse (o lo hubieran hecho de otra manera) los distintos (neo)constitucionalismos, principialistas o garantistas, a saber: el reconocimiento de la fuerza normativa de la Constitución como ley suprema, la incorporación a la misma de un denso contenido material o sustantivo, en particular de derechos fundamentales, la garantía judicial y la rigidez frente a la reforma ${ }^{4}$. A este modelo, inédito en la historia política europea de los últimos doscientos años, se le puede denominar neoconstitucional o de cualquier otra manera que permita iluminar las diferencias entre la fórmula contemporánea y el constitucionalismo sólo nominal del Estado legislativo de Derecho y el constitucionalismo sólo formal que finalmente avalaría KELSEN. Pero, a mi juicio, las cuatro características indicadas representan el presupuesto común a toda concepción (neo) constitucionalista, tanto principialista, argumentativa o iusnaturalista, como positivista y garantista. Las diferencias entre esas concepciones responden entonces al distinto modo de interpretar el alcance o la importancia de tales características.

\section{EL CONSTITUCIONALISMO CONTEMPORÁNEO Y LA TESIS DE LAS FUENTES SOCIALES}

Como he dicho, precisamente ha sido FERRAJOLI quien más ha insistido en que la diferencia fundamental entre el Estado legislativo de Derecho y el Estado constitucional de Derecho reside, no meramente en la presencia de una lex superior, sino en lo que he llamado alguna vez la rematerialización constitucional: frente al carácter sólo formal de las condiciones de validez de las leyes que regirían en el primero, el segundo incorpora también límites y vínculos sustantivos, que condicionan no sólo quién manda y cómo se manda (normas de competencia y procedimiento), sino también qué puede e incluso qué debe mandarse. Allí donde se proclama la dignidad humana, se proscriben las penas crueles o se garantizan la igualdad y el resto de derechos fundamentales, sencillamente la validez de las normas del sistema ya no puede hacerse depender sólo de la legitimidad democrática de su autor, sino ante todo de su adecuación a criterios sustantivos, que a mi juicio no hay inconveniente en calificar como criterios morales.

Pues bien, desde la primera página del trabajo FERRAJOLI confiesa que su finalidad es sostener «una concepción del constitucionalismo estrictamente "iuspositivista", entendiendo por positivismo jurídico una concepción y/o un modelo de Derecho que reconozca como "Derecho" todo conjunto de normas puestas o producidas por quien está habilitado para producirlas, independientemente de sus contenidos y, por tanto, de su eventual injusticia» ${ }^{5}$ : la identificación de lo que es Derecho depende de ciertos

${ }^{4}$ He tratado la cuestión más extensamente en «Neoconstitucionalismos (Un catálogo de problemas y argumentos)», Anales de la Cátedra Francisco Suárez, núm. 44, 2010 (en prensa).

${ }^{5}$ L. FERRAJOLI, «Constitucionalismo principialista y constitucionalismo garantista», epígrafe 1,1 y ss. En la nota 2 insiste FERRAJOLI, recordando a KELSEN, que «no se puede negar la validez de un ordenamiento jurídico positivo a causa del contenido de sus normas». 
hechos y no de juicios morales o de la justicia de sus contenidos. Si no me equivoco, se formula aquí de forma prístina una de las más celebradas tesis positivistas, la tesis de las fuentes sociales del Derecho. Pero, ¿es esto posible?, ¿es posible dar cuenta de la validez o existencia jurídica de las normas en el marco del Estado constitucional a partir de la tesis de las fuentes sociales? Pienso que sí, por lo que se refiere a la Constitución misma, cuya existencia es sin duda una cuestión de hecho, pero, ¿puede decirse lo mismo para el resto de las normas?

La tesis de las fuentes sociales puede entenderse de distintos modos, pero tal vez el más asentado consiste en considerar que el Derecho es un fenómeno que está abífuera, de manera que podemos identificarlo a través de ciertos hechos externos, como el acto de promulgación de las normas por una autoridad o la verificación de una cierta práctica social. Desde esta perspectiva, la identificación del Derecho se convierte en una cuestión de hecho ajena a los problemas de la justicia, y de ahí que pueda predicarse el carácter jurídico de una norma «cualquiera que sea su contenido»: la tesis de las fuentes sociales se ajusta perfectamente al esquema del Estado legislativo de Derecho. Pero justamente esto es lo que no parece tolerar el Estado constitucional de Derecho: aquí las pautas morales ya no sólo aparecen como delegaciones de la Constitución o de la ley para que el juez adopte decisiones incluso cuando el Derecho legal aparezca indeterminado, lo que ha ocurrido siempre con los variados conceptos morales incorporados a la ley, sino que tales pautas se erigen en criterios internos para juzgar la pertenencia de las normas al ordenamiento; es decir, que el razonamiento moral se hace presente, no sólo en la aplicación del Derecho, sino también en su identificación ${ }^{6}$. La existencia de Constituciones con plena fuerza normativa y dotadas de un denso contenido sustantivo o moral impide seguir concibiendo la identificación del resto de las normas del sistema como una mera cuestión de hecho, pues la validez de las mismas descansa no sólo en el respeto a las condiciones formales de competencia y procedimiento, sino también en su adecuación a los principios y derechos fundamentales que representan otras tantas condiciones materiales. Bien puede decirse entonces que los problemas de justicia (más precisamente, de la concepción de la justicia incorporada a la Constitución) se han transformado en problemas de validez o identificación de las normas.

Conviene subrayar que el positivismo o una buena parte del mismo no encuentra ninguna dificultad en considerar la presencia de conceptos sustantivos o morales en la regla de reconocimiento llamada a identificar las normas del sistema; es decir, que la pertenencia de una norma ya no dependería únicamente del becho evidente de su promulgación, sino de que su significado resulte conforme o no contradictorio con los principios de justicia incorporados al Derecho. Tan sólo un positivismo exclusivo o excluyente que sostenga que la validez o identificación de una norma no puede apelar

${ }^{6}$ Una distinción semejante es la que formula RAz entre un razonamiento acerca del Derecho y un razonamiento de acuerdo con el Derecho, La ética en el ámbito público, trad. de M. Melon, Barcelona, Gedisa, 2001, 348 y ss. Aunque para el autor británico el razonamiento acerca del Derecho, que se dirige a la identificación del mismo, excluye el razonamiento moral. También BuLYGIN sostiene que una proposición acerca del Derecho es descriptiva y, por tanto, susceptible de verdad o falsedad, mientras que una proposición conforme al Derecho bien puede estar indeterminada, «Sobre el problema de la objetividad del Derecho», en Las razones de la producción del Derecho, N. CARDINAuX, L. Clérico y A. D’Auria (coords.), Universidad de Buenos Aires, 2006,39 y ss. 
nunca, o necesariamente no puede apelar, a la moralidad, resultaría inadecuado para describir el modelo constitucionalista ${ }^{7}$. Pero, en realidad, esto es algo que tal vez no aceptaría ni el propio KELSEN ${ }^{8}$, que desde luego no aceptaría HART ${ }^{9}$, y que según creo tampoco acepta FERRAJOLI, cuya fundamental distinción entre vigencia y validez gira en torno a la naturaleza fáctica o valorativa de sus respectivos juicios: «Mientras que las condiciones formales de la vigencias constituyen requisitos de becho, las condiciones sustantivas de la validez [...] consisten normalmente en el respeto a valores». Por eso, así como los juicios sobre la vigencia consisten en simples averiguaciones empíricas, los juicios sobre la validez son «juicios de valor, y como tales ni verdaderos ni falsos» ${ }^{10}$. Así pues, la validez de una norma no es que dependa algunas veces de su conformidad con los principios sustantivos, sino que depende siempre; los hechos evidentes, por ejemplo que el Parlamento ha dictado una ley o que el juez ha pronunciado una sentencia, nos sirven sólo para determinar, en terminología de FERRAJOLI, la vigencia o la validez formal, no la validez plena o sustantiva ${ }^{11}$.

\section{EL OBJETIVISMO NEOCONSTITUCIONALISTA}

Desde la perspectiva neoconstitucionalista o principialista, pero creo que también desde la óptica positivista, la conclusión precedente convierte en dramática la opción que se adopte a propósito de la objetividad de los juicios morales, pues si la determinación de qué dice el Derecho depende de qué dice la moral, entonces la objetividad de tales juicios es condición de la objetividad de nuestros juicios acerca de la validez de las normas y, más allá incluso, es condición también de la propia solidez de los fundamentos del Estado democrático basado en la supremacía de la mayoría encarnada por el legislador y en la separación de poderes: dado que la validez de la decisión mayoritaria viene sometida en el Estado constitucional a su conformidad con ciertos principios morales sustantivos, si suponemos que éstos no dicen nada o casi nada, resultaría que los llamados a aplicar tales principios se convertirían en los auténticos señores del Derecho. Sólo admitiendo la objetividad o algún grado de objetividad de los juicios morales parece posible mantener tanto la (relativa) determinación del Derecho, como el sometimiento de la ley precisamente a la Constitución y no a las variables o caprichosas concepciones del bien sostenidas por los diferentes jueces.

\footnotetext{
7 El principal representante de este positivismo sería J. RAZ, La ética en el ámbito de lo público, cit., 227 y ss.

${ }^{8}$ La Constitución puede establecer no solamente los órganos del proceso legislativo, «sino también, hasta cierto grado, el contenido de futuras leyes. La Constitución puede determinar negativamente que las leyes no deben tener cierto contenido [...] Sin embargo, ésta puede también prescribir, en forma positiva, un cierto contenido para futuras leyes», H. KeLSEn, Teoría General del Derecho y del Estado, 1944, trad. de E. García MÁYNEZ, México, UNAM, 1979, 148.

9 Al menos desde el Post scriptum al concepto de Derecho, ed. de R. TAmaYo, México, UNAM, 2000, 51: «De acuerdo con mi teoría, la existencia y contenido del Derecho puede ser identificado por referencia a las fuentes sociales [...] sin recurrir a la moral, excepto donde el Derecho, así identificado, haya incorporado criterios morales para la identificación del Derecho».

${ }^{10}$ L. FerRajoli, Derecho y razón. Teoría del garantismo penal, trad. de P. Andrés, A. Ruiz Miguel, J. C. BAYÓn, J. TERRADIllos y R. CANTARERO, Madrid, Trotta, 1995, 874. La opinión sobre el carácter sólo empírico de los juicios relativos a la vigencia es matizada en Principia Iuris, cit., vol. I., 577, nota 23.

11 Vid. L. FerRajoli, Principia Iuris, cit., vol. I, 568.
} 
Tal vez por esto el neoconstitucionalismo principialista observa una cierta tendencia al objetivismo moral y (alternativa o conjuntamente) propicia el desarrollo de una poderosa teoría de la argumentación que suele presentarse como el centro mismo de toda experiencia jurídica. No es el momento de detenerse en este punto ${ }^{12}$, pero cabe recordar cómo DwORKIN, el gran defensor de la tesis de la unidad de respuesta correcta, parece haber encontrado últimamente en el realismo moral la vía más directa para alcanzarla. Bajo la significativa rúbrica de «Metafísica» y tras criticar a quienes suponen que nuestros conceptos morales son creaciones lingüísticas, «que la verdad objetiva en la moral política no está abi fuera en el universo para que los abogados, jueces y cualquier otro pueda descubrirla», añade: «Pero si la verdad moral objetiva no existe, tampoco hay ninguna tesis interpretativa que pueda ser realmente superior en los casos verdaderamente difíciles [...] Y sobre esta base no podemos sostener un enfoque teórico de la aplicación judicial del Derecho» ${ }^{13}$. Paradójicamente, si las cosas fueran así, podríamos mantener la tesis de las fuentes sociales como antes fue descrita: la identificación del Derecho seguiría siendo una cuestión de becho, aunque, eso sí, de unos muy peculiares bechos morales.

Tengo la impresión de que el objetivismo moral y las teorías de la argumentación jurídica son difícilmente compatibles, aunque algunos neoconstitucionalistas parezcan a veces cultivar ambas cosas al tiempo. Las teorías de la argumentación reposan confesadamente en el constructivismo ético y éste, a su vez, sostiene tesis antimetafísicas y antirealistas ${ }^{14}$. Sin embargo, objetivismo moral y constructivismo ético vienen a satisfacer un mismo designio que resulta fundamental al neoconstitucionalismo, el de poder formular juicios morales con pretensiones de objetividad o certeza; ya sea una objetividad ex ante o previa a la argumentación, más en la tradición iusnaturalista, ya sea una objetividad ex post o fruto de un depurado modelo de argumentación ${ }^{15}$. Lo importante es esquivar el reproche de que, a la postre, el Derecho sea tan sólo lo que los jueces dicen que es.

Precisamente, este reproche resulta habitual en las críticas al neoconstitucionalismo ${ }^{16}$ y es compartido asimismo por FERRAJOLI, para quien, como ya sabemos, los

12 Me permito remitir a mi trabajo «Sobre la identificación del Derecho a través de la moral», en J. J. MoRESO, L. PrIETO y J. FerRer, Los desacuerdos en Derecho, Madrid, Fundación Coloquio Jurídico Europeo, 2010, 87 y ss. Precisamente, el trabajo de MORESO en este mismo volumen, que lleva el curioso título de «Tomates, hongos y significado jurídico» constituye una matizada reivindicación del realismo moral.

13 R. Dworkin, La justicia con toga, trad. de M. Iglesias e I. Ortiz DE UrbinA, Madrid, M. Pons, $2007,73$.

14 Como escribe J. RAWLS, «la idea de aproximarse a la verdad moral no tiene lugar alguno en una doctrina constructivista: las partes en la posición original no reconocen ningún principio de justicia como verdadero o correcto y por ello como previamente dado; su meta es simplemente seleccionar la concepción que para ellos es más racional...», «El constructivismo kantiano en la teoría moral», en Justicia como equidad, ed. de M. A. Rodilla, Madrid, Tecnos, 1999, 213 y 254 y ss. El pluralismo moral que entraña esta posición está muy presente asimismo en la teoría de la argumentación de R. ALEXY: «Al menos en las sociedades modernas, hay diferentes concepciones para casi todos los problemas prácticos. Los consensos fácticos son raros [...] En el conjunto de un ordenamiento jurídico se pueden encontrar siempre valoraciones divergentes que pueden ponerse en relación, pero de manera distinta, con cada caso concreto...», Teoría de la argumentación jurídica, trad. de M. Atienza e I. EsPejo, Madrid, CEC, 1989, 33.

15 Vid. A. García Figueroa, Criaturas de la moralidad. Una aproximación neoconstitucionalista al Derecho a través de los derechos, Madrid, Trotta, 2009, 34 y ss.

16 Entre nosotros, tal vez uno de los más tenaces críticos del neoconstitucionalismo sea J. A. GARCíA AmAdo, a partir por cierto de unos argumentos muy cercanos a los de FERRAJOLI. Vid., entre otras agudas 
juicios sobre la validez son juicios de valor y, como tales, ni verdaderos ni falsos. Que la determinación de los más decisivos conceptos jurídicos dependa en última instancia de juicios morales presentados además bajo la aureola de una presunta objetividad, supondría desde esta perspectiva crítica una apertura al activismo judicial y al pandectismo: la normatividad del Derecho se disolvería en la argumentación particularista, las prerrogativas del legislador se verían permanentemente acosadas por la interpretación judicial, el Derecho válido terminaría reduciéndose al Derecho eficaz y, en fin, el pluralismo moral característico de una sociedad democrática quedaría asfixiado por una presunta moral oficial (constitucional) argumentativamente descubierta por unos nuevos sacerdotes, los jueces, oráculos a un tiempo del Derecho y de la justicia. Pero justamente si todo esto sucede o se teme que suceda es porque no se comparten los presupuestos que han sido descritos; esto es, porque no se comparte la idea de una moral objetiva y cognoscible que permita considerar la identificación del Derecho como una cuestión precisamente objetiva aunque dependiente de la moralidad. Como en ocasiones sucede, las divergencias jurídicas entrañan desacuerdos morales. Para FERRAJOLI, en efecto, el neoconstitucionalismo reposa irremediablemente en un objetivismo moral y en un cognoscitivismo ético que resultan inaceptables y que, sin embargo, están en la base de sus dos desarrollos fundamentales, el constitucionalismo ético y el principialismo ponderativo.

\section{SOBRE LA CONEXIÓN NECESARIA ENTRE DERECHO Y MORAL}

El neoconstitucionalismo principialista sostiene la conexión necesaria entre el Derecho - al menos el Derecho de los modernos Estados constitucionales, que son los únicos que interesan a una concepción que no tiene inconveniente en confesarse «particular» ${ }^{17}$ - y la moral a través de distintas vías argumentales: una primera que supone la apertura o ampliación del orden jurídico mediante la directa incorporación al mismo de valores morales objetivos ${ }^{18}$; una segunda que implica, al contrario, su restricción o limitación merced a la eliminación de sus normas notoriamente injustas ${ }^{19}$; y una tercera que, invirtiendo los términos de la relación, concibe al propio orden jurídico constitucional y democrático como un centro generador de la moral, como una suerte de fábrica de la eticidad ${ }^{20}$. Los dos primeros argumentos, de clara evocación iusnaturalista, suponen que la moral desempeña una función de identificación del Derecho; el tercero, en cambio, parece aproximarse más al positivismo ético y aquí es el Derecho quien desempeña una función de identificación de la moral. En otros lugares he tenido oportunidad de manifestar mi opinión sobre esta dimensión del neoconstitucionalismo, que es del todo coincidente con las críticas formuladas por FERRAJOLI. Sin embargo, al hilo de su lectura me permito añadir dos observaciones.

contribuciones, «Derecho y pretextos. Elementos de crítica del neoconstitucionalismo», en Teorías del neoconstitucionalismo, ed. de M. CARBONELL, Madrid, Trotta, 2007, 237 y ss.

17 Vid. A. García Figueroa, Criaturas de la moralidad, cit., 222 y ss.

18 Por ejemplo, R. DwORKIN y su tesis de que la validez de algunas normas no depende de ningún hecho evidente sino sólo de su moralidad, Los derechos en serio, trad. de M. GuASTAVINO, Barcelona, Ariel, 1984, 65.

19 Éste es el famoso argumento de RADBRUCH recreado por R. ALEXY, El concepto y la validez del Derecho, trad. de J. M. SEÑA, Barcelona, Gedisa, 1994, 45. Una óptima presentación de este argumento desde perspectivas neoconstitucionalistas en A. GARCÍA FIGUEROA, «Injusticia extrema y validez del Derecho» (en prensa).

20 Aquí el ejemplo bien podría ser C. S. NinO, Derecho, moral y política, Barcelona, Ariel, 1994, 188 y ss. 
La primera es que el neoconstitucionalismo, tomado en su conjunto, resulta en este punto contradictorio; más concretamente, que los dos primeros argumentos son en el fondo incompatibles con el tercero. A mi juicio, el constructivismo ético y, sobre todo, la ética discursiva que están detrás del tercer argumento pulverizan las premisas mismas del constitucionalismo rematerializado como límite a lo que puede ser democráticamente acordado: si resulta que la democracia es el sucedáneo del discurso moral y la moralidad que resulta unida al Derecho «se ha desembarazado de todo contenido normativo determinado y convertida en un procedimiento de fundamentación de contenidos morales posibles» ${ }^{21}$, si esto es así, sencillamente no se comprende que algunas normas puedan ser jurídicas sólo por su valor moral si no han pasado antes por el tamiz de la democracia, es decir, si no son identificables mediante los hechos que constituyen el procedimiento democrático, fuente a un tiempo de la moralidad y del Derecho; y se comprende mucho menos el argumento de RADBRUCH, pues desde estas premisas resulta lógicamente imposible que un Derecho democrático produzca normas notoriamente injustas, dado que la democracia ha sido revestida de un valor epistemológico. El constructivismo y la ética del discurso no militan así a favor de un constitucionalismo fuerte, sino, más bien al contrario, de una democracia basada sólo en el principio mayoritario. De manera que si con la apelación al constructivismo se ha pretendido sustituir el solipsismo por el diálogo y la autonomía por la heteronomía, lo que no puede pretenderse también es fundar normas morales y jurídicas al margen del procedimiento democrático, o sea del Derecho positivo, ni invalidar normas nacidas de ese mismo procedimiento. Y, al contrario, si quiere mantenerse la idea de que algunas normas morales ingresan en el Derecho sólo por ser morales (y, por tanto, en algún sentido, objetivas) y que algunas normas jurídicas pierden su condición por resultar inmorales o injustas, entonces la apelación al procedimiento democrático como fuente única de la justicia resulta del todo improcedente.

La segunda observación se refiere al tipo de relación que es posible trazar entre las distintas concepciones del Derecho y las doctrinas éticas y metaéticas. En este sentido, FERRAJOLI parece sostener que el objetivismo moral y el cognoscitivismo ético constituyen rasgos característicos de todo neoconstitucionalismo, como de todo iusnaturalismo, y a su vez también que ambas posiciones son incompatibles con el positivismo ${ }^{22}$. Sin duda, es una idea bastante extendida que el positivismo incorpora un cierto punto de vista sobre la moral y el conocimiento moral ${ }^{23}$. Y es cierto que particularmente los dos primeros argumentos antes señalados parecen requerir ese compromiso ético y metaético: afirmar que algunas normas son jurídicas precisamente porque son morales o, al contrario, que otras normas jurídicas dejan de serlo por su carácter inmoral, es difícilmente sostenible si no se parte de algún objetivismo y cognitivismo. Sin embargo, y aun suponiendo que esto resulte acertado, me parece más discutible la afirmación

${ }^{21}$ J. HABERMAS, «¿Cómo es posible la legitimidad por vía de legalidad?», en Estudios sobre moralidad y eticidad, trad. de M. JIMÉNEZ REDONDO, Barcelona, Paidós, 1981, 168.

22 Se cuida de advertir, no obstante, que la alternativa no es el puro emotivismo ni el abandono de la argumentación racional, «Constitucionalismo principialista y constitucionalismo garantista», cit., epígrafe 4.A), 25.

${ }^{23}$ E. Bulygin ha sostenido incluso que el escepticismo ético forma parte del positivismo jurídico, «Sobre el estatus ontológico de los derechos humanos», en C. AlCHOURRÓn y E. BuLYGIN, Análisis lógico y Derecho, Madrid, CEC, 1991, 623. No cabe duda que conspicuos positivistas, como KELSEN o Ross, permiten fundamentar esa asociación. 
contraria, esto es, que dichas posiciones éticas se muestren necesariamente incompatibles con el positivismo.

A mi juicio no es así; no es una verdad necesaria que el positivista en Derecho haya de renunciar a todo objetivismo moral o al cognoscitivismo ético ${ }^{24}$. El positivismo entraña tan sólo una concepción a propósito del Derecho como fenómeno social estrechamente vinculado al uso de la fuerza y separado de la moral crítica o racional, cualquiera que ésta sea y cualquiera que sea nuestro punto de vista sobre la justicia. Por ejemplo, no veo ningún inconveniente para que quien asuma como propia una moral objetiva y heterónoma como es la moral católica, reconozca sin embargo el carácter jurídico de una norma injusta ${ }^{25}$, y al mismo tiempo rechace ese calificativo para otras normas que él considera moralmente obligatorias pero que carecen del respaldo del Derecho. Afirmar que la validez de la norma no depende de su contenido de justicia y, por tanto, que pueden existir normas válidas e injustas y que la sola justicia no convierte a una norma en jurídica, me parece compatible con los mayores excesos objetivistas y cognoscitivistas a propósito de la moral. Por ello, no veo ningún inconveniente en escindir el discurso práctico y mostrarse como un «iusnaturalista» partidario del objetivismo y del cognoscitivismo en materia moral y como un positivista en Derecho. Es más, recomendar la desobediencia o la insumisión frente a la ley injusta tampoco representa un desmentido al positivismo, al menos al positivismo de quienes pensamos que la obligatoriedad (moral, naturalmente) no es un rasgo conceptual del Derecho ${ }^{26}$, o simplemente al que en todo caso mantenga «la primacía práctica de la moral y de la justicia sobre el Derecho, que justifica la desobediencia civil contra el Derecho injusto» ${ }^{27}$. En cambio, el positivismo jurídico sí me parece incompatible con la tercera forma de conexión entre el Derecho y la moral, aquella que suele recurrir al constructivismo y considerar al Derecho (democrático) como fuente de la moralidad y de la justicia, postulando así una conexión necesaria entre Derecho y moral en la línea del positivismo ético.

\section{PRINCIPIOS, CONFLICTOS Y DERECHOS}

Tengo la impresión de que el debate acerca de la distinción entre principios y reglas, muy animado hace algo más de una década, ha perdido fuerza o virulencia, en parte tal vez porque la propia discusión ha contribuido a acercar y matizar las distintas posiciones. En líneas generales, creo que la opinión de FERRAJOLI se adscribe a un positivismo no neoconstitucionalista que pudiera resumirse así: la distinción fuerte entre reglas y principios es errónea e infundada, y la distinción débil, aunque resulta

24 Así lo ven también P. ComANDUCCI, «Derecho y moral», en Hacia una teoría analítica del Derecho. Ensayos escogidos, Madrid, CEPC, 2010, 64; y J. WALDRON, Derechos y desacuerdos, trad. de J. L. MARTÍ y A. Quiroga, Madrid, M. Pons, 198.

25 Este es, por ejemplo, el caso de A. OLLERO: «Optar por proclamar enfáticamente la no juridicidad de la ley injusta resulta una curiosa alternativa [...] (las normas injustas) son sin duda Derecho; un pésimo Derecho, que merecería verse civilmente desobedecido e incluso derogado por una eficaz desuetudo, si se contara con el preciso heroísmo cívico», El Derecho en teoría, Pamplona, Thomson, Aranzadi, 2007, 244.

$26 \mathrm{Y}$ en esto está de acuerdo FERRAJOLI, «Constitucionalismo principialista y constitucionalismo garantista», cit., epígrafe 4.A), 26.

27 L. FerRAJOLI, Principia Iuris, cit., vol. II, 101. 
acertada, se muestra poco relevante. Comparto varias de sus observaciones críticas, en especial la relativa a la inicial distinción entre la aplicación, que sería el rasgo típico de las reglas, y el respeto, que sería lo máximo a lo que podrían aspirar los principios. Me parece evidente que también las reglas, cuando son observadas por sus destinatarios, resultan respetadas; y que los principios y más concretamente los derechos fundamentales, cuando son violados, resultan aplicables del mismo modo que las reglas. A mi juicio, la dificultad reside en determinar, no aquello que debe ocurrir cuando en definitiva se decide su aplicación, sino las condiciones en que cabe decir que un principio debe ser aplicado como consecuencia de su violación. En otras palabras, la ponderación no sustituye a la aplicación, no es su alternativa, sino que la precede y eventualmente la desplaza o evita; según el esquema ponderativo, la lesión de un derecho no es todavía una razón concluyente para su aplicación porque puede ocurrir que deba ceder ante otro principio o derecho, aunque, si finalmente se aplica, no presenta peculiaridad $\operatorname{alguna}^{28}$.

Por eso, ni el enfoque que parte de la distinción estructural entre reglas y principios, ni aquel otro que insiste en la presunta oposición entre ponderación y subsunción, me parece que iluminen mucho los problemas. La ponderación debe enmarcarse más bien en el capítulo de las antinomias, concretamente de aquellas antinomias donde resulten insuficientes o improcedentes los clásicos criterios jerárquico, cronológico y de especialidad. De entrada, que hablemos de antinomias supone que nuestro caso debe poder ser subsumido en el ámbito de aplicación de dos normas que suministran razones contradictorias. Y que tales antinomias no puedan resolverse mediante los criterios tradicionales supone que efectivamente se acredite esa insuficiencia, lo que no siempre resultará evidente, sobre todo en relación con el criterio de especialidad. De ahí que la ponderación sólo se muestre operativa respecto de normas del mismo nivel jerárquico, coetáneas y de semejante grado de generalidad/especialidad, lo que singularmente ocurre con algunas normas constitucionales ${ }^{29}$. Creo que esto incluso puede ser compartido por FERRAJOLI ${ }^{30}$ y, así entendida, también sería posible reconducir la ponderación a sus justos límites, dejando de ser esa especie de talismán para justificar los más osados ejercicios interpretativos ${ }^{31}$; sencillamente, sería un método para re-

28 Lo dicho en el texto tal vez se entienda mejor si distinguimos entre un juicio prima facie y un juicio definitivo, una distinción ausente en FERRAJOLI, pero de capital importancia en los esquemas ponderativos. En pocas palabras, significa que la inicial constatación de que se ha producido la afectación de un derecho no supone sin más su triunfo o su aplicación, sino que abre las puertas a un examen ulterior a la luz de los demás derechos o principios concurrentes (la ponderación propiamente dicha), examen que desemboca en el juicio definitivo. Vid. C. BERNAL, El principio de proporcionalidad y los derechos fundamentales, Madrid, CEPC, 2003, 614 y ss.

${ }_{29}$ No todas, ciertamente. El criterio de especialidad es aplicable en no pocos conflictos: por ejemplo, la preferencia del varón sobre la mujer en la sucesión a la Corona (art. 57.1 CE) es una excepción al principio de igualdad del art. 14; y la prohibición de las asociaciones secretas o paramilitares (art. 22.5 CE) es otra excepción, esta vez al derecho de asociación.

30 Los que llama principios regulativos «son vinculantes e indefectibles si no encuentran límites en normas del mismo nivel» que a su vez tampoco puedan operar según el criterio de especialidad, «Constitucionalismo principialista y constitucionalismo garantista», epígrafe 6.C), 44 (la cursiva es nuestra). Luego los principios regulativos dejan de ser vinculantes e indefectibles cuando encuentran límites al mismo nivel que no puedan operar de acuerdo con la regla de la especialidad.

31 El desbocado activismo judicial a partir de los principios, en algunas ocasiones simplemente inventados por el propio juez, tal vez reciba impulso por parte del neoconstitucionalismo principialista, como denuncia FERRAJOLI, pero se articula más bien mediante la venerable figura de los principios generales del Derecho, 
solver cierto tipo de contradicciones normativas particularmente complejas, pero en ningún caso una fábrica de caprichosas normas o principios.

Pero no estoy tan seguro de que, como sugiere FERRAJOLI, la ponderación sea un recurso para resolver sólo los «casos difíciles», marginales y más o menos excepcionales. Al contrario, el panorama descrito en el párrafo anterior es bastante común, tal vez por la indeterminación y no condicionalidad de los principios y derechos constitucionales, que hace relativamente fácil subsumir un buen número de casos en sus respectivos ámbitos de aplicación, sin que entre éstos se advierta siempre una clara relación de especialidad. No es ocasión de un análisis de detalle, pero quisiera comentar un ejemplo paradigmático de relevancia de la ponderación que sin embargo FERRAJOLI parece considerar un caso de aplicación ordinaria de reglas. Me refiero al principio de igualdad y a la prohibición de discriminación. La Constitución española —al igual que la italiana, art. 3- tras proclamar la igualdad ante la ley, añade una serie de «criterios prohibidos», como el nacimiento, la raza, el sexo o la religión, lo que, interpretado al modo subsuntivo, significa que tales elementos no deben tomarse nunca como criterios para adscribir posiciones de derecho o de deber; es decir, que parece que los derechos y los deberes han ser los mismos con independencia de la raza, el sexo, etc. Sin embargo, esto no es así y tampoco puede serlo si se desea reconocer algún contenido a la llamada igualdad sustancial (arts. 9.2 de la Constitución española y 3.2 de la italiana) que estimula acciones positivas a favor de los grupos desfavorecidos, grupos que a veces se definen según los «criterios prohibidos» ${ }^{32}$, y últimamente también tipificaciones penales en las que se ve reflejada una suerte de discriminación inversa ${ }^{33}$. Me parece claro que cualquiera de estas medidas constituye, al menos prima facie, una violación $\mathrm{o}$, si se prefiere, una afectación de la igualdad formal y también que, en definitiva, no toda intervención promocional puede reputarse aceptable, aunque algunas sí lo sean. Sin embargo, decidir cuáles sí y cuáles no, se hace depender de un juicio de ponderación que algunos llaman de razonabilidad ${ }^{34}$, sin duda ampliamente discrecional, pero en todo caso inevitable para la coexistencia de los principios en pugna.

Pero, en realidad, si para FERRAJOLI los conflictos y las ponderaciones tienen un carácter excepcional es porque logra introducir en el seno mismo del sistema de derechos un principio de jerarquía, no jurídica ni axiológica, sino estructural: lógicamente, allí donde existe una relación jerárquica no hay espacio para la ponderación. En otro lugar he sostenido que FERRAJOLI pudiera adscribirse a la llamada teoría interna de los derechos fundamentales, que propugna la eliminación misma de los conflictos me-

una auténtica fábrica de producción normativa mediante argumentación y primer gran desmentido al legalismo positivista incrustado en el corazón mismo del sistema de fuentes. Me permito remitir a mi Ley, principios, derechos, Madrid, Dykinson, 1998, 49 y ss.

32 El propio FERRAJOLI aprueba las medidas que benefician a la mujer y rompen la estricta igualdad formal, precisamente con el objetivo de compensar discriminaciones seculares y «recomponer» así una igualdad inexistente en la práctica. Vid. Principia Iuris, cit., vol. I, 798 y ss.

33 A mi juicio, se trata de un recusable uso simbólico del Derecho penal, pero el legislador ha querido subrayar lo intolerable de la llamada violencia de género (normalmente contra la mujer) diseñando tipologías en las que se hace uso del criterio del sexo del sujeto infractor. Éste es el caso del art. 153.1 del Código Penal, sobre el que se pronuncia el Tribunal Constitucional en Sentencia 59/2008.

34 Sobre las relaciones entre razonabilidad y ponderación, vid. C. BERNAL, «Racionalidad, proporcionalidad y razonabilidad en el control de constitucionalidad de las leyes», en El Derecho de los derechos, Bogotá, Universidad Externado de Colombia, 2005, 59 y ss. 
diante una presunta interpretación adecuada del ámbito de cada uno de los derechos, pero ahora debo matizar esa opinión ${ }^{35}$ : aquí los conflictos quedan eliminados o, mejor dicho, se transforman en violaciones de unos derechos a manos de otros merced a que entre ellos existe una suerte de jerarquía u orden de prelación. Muy sintéticamente, ese orden sería el siguiente: en lo más alto se sitúan las inmunidades, como el derecho a la integridad o a no ser torturado, que en puridad no pueden entrar en conflicto con nadie por la sencilla razón de que no se ejercen; las inmunidades se respetan o se violan. A continuación aparecen las facultades o libertades de hacer, como la libre expresión o el derecho de manifestación, que no encuentran más restricciones que las exigidas por el respeto a las inmunidades y al resto de los derechos-facultad. En tercer lugar se colocan los derechos autonomía, cuya expresión son los negocios jurídicos en el ámbito privado y las leyes en el público, y que están estrictamente limitados por los derechos precedentes; los derechos autonomía son en realidad derechos-poder que en puridad no colisionan, sino que en su caso constituyen una violación sobre el resto de derechos. Finalmente, la libertad natural o esfera del agere licere que nace del silentium legis, llamada a ser libremente limitada por el ejercicio de los derechos autonomía ${ }^{36}$. Como es obvio, vistas así las cosas, se reducen drásticamente las posibilidades de conflicto: donde el principialismo ve conflictos, FERRAJOLI suele ver violaciones.

No procede un análisis de detalle, pero a mi juicio las divergencias entre estas dos formas de entender el Estado constitucional pueden ser analizadas en planos diferentes. En el plano descriptivo, las posiciones neoconstitucionalistas o principialistas seguramente dan cuenta de una forma más ajustada de cómo funcionan nuestros sistemas jurídicos y de cuál es la práctica habitual de sus operadores: por ejemplo, cuando una ley entra en conflicto (o viola) un derecho fundamental, la jurisprudencia no se plantea una colisión entre el derecho de autonomía que está detrás de la ley y el derecho objeto de restricción, como sugiere FERRAJOLI que debe de hacerse, sino entre este último y el principio o derecho que pretende ser protegido por la medida limitadora. Por ejemplo, si una ley sobre medio ambiente impone límites al derecho de propiedad, no se habla de colisión entre el derecho de autonomía expresado en la ley y el derecho de propiedad, sino entre éste y el derecho al medio ambiente ${ }^{37}$. Esto es consecuencia también del llamado efecto irradiación o impregnación: cualquier conflicto jurídico puede ser constitucionalizado mediante su transformación en un conflicto de principios, justamente de aquellos principios que supuestamente ofrecen respaldo a cada uno de los elementos en pugna. Mediante esta sencilla operación desaparece todo rastro de jerarquía entre los derechos, pues no es la ley (el derecho-poder de autonomía) quien viene a limitar la libertad o algún otro derecho fundamental, sino el principio o valor al que dice servir la ley (la seguridad, la garantía de un derecho social, etcétera).

35 Esto ya fue advertido por G. P. LOPERA, Principio de proporcionalidad y ley penal, Madrid, CEPC, 2006, 150 y ss.

${ }^{36}$ He tratado el tema con mayor amplitud en «Principia Iuris: una teoría del Derecho no (neo)constitucionalista para el Estado constitucional», Doxa, núm. 31, 2008, 340 y ss.

37 El ejemplo tal vez no sea muy feliz habida cuenta de la posición de FERRAJOLI sobre el derecho de propiedad o los derechos patrimoniales, y sobre ello, vid. Principia Iuris, cit., vol. I, 759 y ss. Sin embargo, el caso puede reconstruirse con cualquier otro derecho: si una ley limita la libertad religiosa en nombre de la laicidad — v. gr. prohibiendo el velo islámico — u otra ley limita la libertad de manifestación en nombre del orden público, el asunto no se plantea como un conflicto entre la ley y los derechos afectados, sino entre éstos y los principios o derechos invocados por la ley. 
En el plano normativo, garantismo y constitucionalismo principialista parecen tomar también caminos opuestos. El garantismo estimula una mayor intensión de los derechos, es decir, una mejor y mayor protección en especial de los derechos más básicos: en concreto, las inmunidades adquieren una fuerza granítica y no pueden ser sacrificadas en nombre de nada. Aquí reside justamente el mayor riesgo del principialismo, pues la ponderación responde a una lógica abiertamente consecuencialista de pesos y balanceos que puede llegar a legitimar las más invasivas intervenciones en la esfera de los derechos. Para decirlo más claramente, una ley que autorizara el derribo de aviones para evitar un atentado al estilo del 11 de septiembre ${ }^{38}$, u otra que permitiera el uso de la tortura para obtener información sobre un inminente plan terrorista, bien podrían encontrar justificación desde posiciones principialistas, pero en ningún caso desde el garantismo. En mi modesta opinión, aquí el garantismo no es que tenga razón, es que debe tenerla de manera perentoria si no queremos arruinar los derechos más básicos en el altar de la razón de Estado, cuya falta de razón siempre podrá invocar algún principio en su favor. A cambio, el principialismo puede propiciar una mayor extensión de los derechos, esto es, la posibilidad de ampliar el catálogo de posiciones iusfundamentales a partir del reconocimiento de un derecho general de libertad ${ }^{39}$; lo que no parece compatible con la más rígida estructura que adoptan los derechos en la visión garantista, donde la simple libertad natural está llamada a ser objeto de limitación por leyes y negocios jurídicos ${ }^{40}$.

\section{ARGUMENTACIÓN, DISCRECIONALIDAD Y DISEÑO INSTITUCIONAL}

FERRAJOLI y el neoconstitucionalismo principialista creo que coinciden al menos en un aspecto, que es su rechazo de la que pudiéramos llamar versión normativa del realismo jurídico, esto es, aquella que sostiene, no ya en el plano descriptivo que el Derecho es - a veces o siempre- lo que los jueces dicen que es, sino que defiende con mayor o menor énfasis que así debe ser. Aun cuando FERRAJOLI censura la deriva realista a la que arrastrarían muchos planteamientos principialistas, lo cierto es que sus más caracterizados representantes no son realistas en este sentido normativo ${ }^{41}$. Se comparte así el principio de separación de poderes: el juez debe asumir un papel pasivo y cognoscitivo, un papel que recomienda la máxima restricción de las esferas de discrecionalidad y que en todo caso impide una creación libre de Derecho o el desarrollo autónomo de un Derecho de juristas. Tal vez el énfasis sea distinto, pero el modelo de juez ilustrado, boca muda que pronuncia las palabras de la ley, sigue por

38 Como la Ley alemana de seguridad aérea de 14 de enero de 2005, en este punto invalidada por Sentencia del Tribunal Constitucional de 15 de febrero de 2006.

39 Por ejemplo, R. AleXy, Teoría de los derechos fundamentales, trad. de E. GARZÓn, Madrid, CEPC, 1993,331 y ss.

40 No obstante, conviene advertir que FERRAJOLI admite últimamente de modo expreso la figura de los derechos implícitos obtenidos a partir de los derechos expresamente establecidos, «Intorno a Principia Iuris. Questioni epistemologiche e questioni teoriche» (inédito), 14.

41 Ni siquiera ZAGREBELSKY, a quien corresponde el calificativo de «los nuevos señores del Derecho» referido a los jueces. El fino análisis que desarrolla en El Derecho dúctil me parece que está escrito en clave descriptiva y no normativa, trad. de M. GASCón, Madrid, Trotta, 1995, 150 y ss. 
tanto presente, si no como una realidad en el plano descriptivo, sí al menos como un ideal regulativo. Y coinciden también en reivindicar una nueva ciencia de la legislación capaz de imprimir un mayor grado de racionalidad en la producción normativa, considerando que esa racionalidad de la ley representa la mejor garantía del ideal cognitivo de la jurisdicción ${ }^{42}$.

Las divergencias giran de nuevo en torno al ya comentado problema de la objetividad, en especial de la objetividad de los principios morales incorporados a la Constitución y de la forma de argumentar a partir de los mismos. Para las posiciones principialistas la ponderación y en general la argumentación jurídica proporcionan un modelo de objetividad y racionalidad que permite que sea el juez quien pronuncie la última palabra sobre el significado de la Constitución sin comprometer con ello su ideal pasivo y cognoscitivo. Tal vez la posición más extrema sea la representada por DwORKIN, cuyo juez Hércules resulta ser a un tiempo sumamente activo (o activista) en la defensa de los derechos contra la ley y en ausencia de ley (los derechos como triunfos frente a la mayoría), pero también exquisitamente deferente con la Constitución, de la que, gracias a ese objetivismo moral que ya fue señalado, es capaz de extraer nada menos que la única respuesta correcta en cada caso. Pero en general todos los cultivadores de las teorías de la argumentación defienden como poco un «objetivismo mínimo» ${ }^{43}$ sin el que, en verdad, buena parte de su esfuerzo resultaría baldío; y, sobre todo, sin el que la figura del juez que antes fue descrita se vendría abajo en el marco del constitucionalismo principialista. Pero FerRAJOLI no comparte esta fe en las virtudes de la argumentación y de la ponderación; en particular, esta última presenta un carácter fuertemente discrecional y político que fomenta un excesivo activismo judicial y que por ello mismo lesiona la única fuente de legitimidad de la jurisdicción, que es justamente su carácter cognitivo. Asumiendo los planteamientos positivistas tradicionales, el constitucionalismo garantista reconoce que en todo acto de aplicación del Derecho aparece una irremediable discrecionalidad, fisiológica si se quiere, pero reprocha al neoconstitucionalismo principialista que, haciendo del vicio virtud, termine conduciendo a una especie de apoteosis de la discrecionalidad y, con ello, del activismo judicial. Con lo que a la postre el neoconstitucionalismo desemboca en realismo.

Por supuesto, FERRAJOLI reconoce el importante papel de la argumentación jurídica y especialmente de la ponderación como herramientas para imprimir mayor racionalidad en la aplicación del Derecho, pero rechaza el excesivo alcance que en la práctica vienen desempeñando para justificar «un poder de elección en orden a cuáles principios aplicar y cuáles no aplicar sobre la base de la valoración -inevitablemente discrecional- de su diversa importancia» ${ }^{44}$. Según él, lo que en verdad se ponderan no son las normas, sino las singulares e irrepetibles circunstancias de hecho que deben valorarse en la dimensión equitativa de todo juicio, dentro del ordinario poder de connotación equitativa de los hechos que corresponde al juez: bajo el paradigma

42 Esto es algo que a veces se pasa por alto, pero que está muy presente en la filosofía de la Ilustración: la racionalidad de la jurisprudencia descansa ante todo en la racionalidad de la ley; vid., por ejemplo, el capítulo 16 del libro XXIX de El espíritu de las leyes. La apertura de la teoría de la argumentación a la esfera legislativa es patente en M. ATIEnzA, Contribución a una teoría de la legislación, Madrid, Civitas, 1997; vid. también la monografía de G. MARCILLA, Racionalidad legislativa, Madrid, CEPC, 2005, 313 y ss.

43 Vid. M. ATIEnZA, El Derecho como argumentación, Barcelona, Ariel, 2006, 53.

${ }^{44}$ L. FERRAJOLI, «Constitucionalismo principialista y constitucionalismo garantista», cit., epígrafe 6.C), 47. 
garantista, los jueces no pueden crear o ignorar normas, sino sólo decidir sobre su aplicación o no aplicación a la vista de las circunstancias de hecho. Los ejemplos que propone en este sentido son bastante elocuentes y creo que ninguno tiene que ver con la ponderación entre principios constitucionales.

Aunque las palabras de FERRAJOLI sobre la ponderación podrían interpretarse poco más que como una apelación al buen juicio o al sentido común, todavía creo que cabe ensayar una aproximación entre su postura y la generalmente sostenida desde el neoconstitucionalismo. Para la concepción principialista o más argumentativa la ponderación supone sin duda «pesar» la importancia relativa de las normas, pero justamente ese peso depende de las circunstancias de hecho, y por eso es un peso variable en cada caso. En resumidas cuentas, el objeto de la ponderación es «cerrar» las condiciones de aplicación de los principios, es decir, determinar en qué casos uno debe triunfar sobre otro y, con ello, decidir sobre su aplicación a la vista de las circunstancias del caso ${ }^{45}$; que es, si no me equivoco, lo que propone FERRAJOLI cuando dice que lo que se ponderan no son normas sino hechos. Recurriendo a un ejemplo paradigmático, reconocer preferencia al derecho a la información sobre el derecho a la intimidad — siendo ambos relevantes y, por tanto, susceptibles de subsumir el caso- es algo que se hace y que sólo se puede hacer a la vista de las circunstancias de hecho concurrentes en el caso; por cierto, a veces tan irrepetibles que pueden fundar un reproche de «particularismo».

Sin embargo, al menos creo que hay dos razones que desaconsejan ese intento de conciliación y que convierten las divergencias en insuperables. Una ha sido ya abordada y es el muy limitado «conflictualismo» de FERRAJOLI, siendo así que el conflictualismo constituye el presupuesto de la ponderación y de su extraordinario desarrollo: allí donde hay relaciones de jerarquía, como las que propone el constitucionalismo garantista, no hay ponderación. La segunda razón tan sólo puede ser aquí sugerida y, a mi juicio, no tiene tanto un carácter teórico cuanto de diseño institucional. Me refiero al distinto modo de enfocar las antinomias entre ley y Constitución y de arbitrar sus formas de resolución. Sin duda, la ponderación es profusamente utilizada por los Tribunales Constitucionales como un método de decisión útil en todo género de procedimientos, incluido el control abstracto sobre la ley ${ }^{46}$. Pero la ponderación parece mostrar también una gran virtualidad en la aplicación de la Constitución y de la ley por parte de los jueces ordinarios, propiciando el desarrollo de técnicas desaplicadoras: dado que el juicio de ponderación o proporcionalidad por definición no desemboca en la declaración de invalidez de ninguna de las normas en pugna, pues son normas constitucionales, permite también desplazar la aplicación de la ley adscrita o amparada por el principio circunstancialmente derrotado mediante una interpretación conforme y sin necesidad de cuestionar su validez constitucional ${ }^{47}$.

FERRAJOLI, por el contrario, parece rechazar que la interpretación judicial sea una vía adecuada para colmar lagunas o resolver antinomias, tal vez como nuevo tributo

45 Esta imagen coincide o se aproxima bastante a la caracterización que hacen ATIENZA y RUIZ MANERO de los principios en sentido estricto, Las piezas del Derecho, Barcelona, Ariel, 1996, capítulo I.

46 Aunque es desaconsejada para este menester por algunos constitucionalistas, como J. JimÉnEZ CAMPO, Derechos fundamentales. Concepto y garantías, Madrid, Trotta, 1999, 77 y 80.

47 He desarrollado más esta idea, precisamente en diálogo con FERRAJOLI, en «Principia Iuris: una teoría del Derecho no (neo)constitucionalista para el Estado constitucional», cit., 337 y ss. 
al principio de positividad ${ }^{48}$; en particular, cuando se advierte una antinomia entre la ley y la Constitución sólo el propio legislador o el Tribunal Constitucional (que es un legislador negativo) están en condiciones de resolverla mediante un acto de derogación o de anulación. A lo que hay que añadir la poca simpatía que muestra FERRAJOLI ante el llamado modelo difuso de justicia constitucional ${ }^{49}$, que es, por su carácter de juicio concreto o a la vista de las circunstancias del caso, seguramente el más acorde con los esquemas neoconstitucionalistas. Se aprecia, pues, una divergencia de fondo, pero a mi juicio no tanto acerca de cómo funciona la técnica ponderativa, sino sobre todo acerca de las circunstancias de la misma y de la competencia institucional para resolver lagunas y antinomias entre ley y Constitución. Sobre lo primero, el garantismo ofrece una imagen de los principios y derechos no conflictualista, o mucho menos conflictualista de lo que es común en los enfoques principialistas y argumentativos; sobre lo segundo, y tal vez por las mismas razones, expulsa del ámbito de la interpretación ordinaria la resolución de lagunas y antinomias que, en cuanto que entraña un acto creador de Derecho, debe quedar confiada al legislador, positivo o negativo.

48 «Antinomias y lagunas en el sentido aquí definido no son inmediatamente solventables por el intérprete, a quien no compete la alteración del Derecho vigente aplicable aun cuando ilegítimo. Requieren, en efecto, para ser removidas, la intervención de específicos actos decisionales: precisamente, la anulación de las decisiones inválidas o la introducción de las decisiones que faltan», Principia Iuris, cit., vol. I, 687.

49 Vid. Principia Iuris, cit., vol. II, 93-94. 